\title{
Antimutagenic and radioprotective activities of beta-carotene against the biological effects of iodine-131 radiopharmaceutical in Wistar rats
}

\author{
A.P. Berti ${ }^{1}$, E. Düsman ${ }^{1}$, R.G. Mariucci ${ }^{1}$, N.B. Lopes $^{2}$ and V.E.P. Vicentini ${ }^{1}$ \\ ${ }^{1}$ Laboratório de Mutagênese e Monitoramento Ambiental, \\ Departamento de Biotecnologia, Genética e Biologia Celular, \\ Universidade Estadual de Maringá, Maringá, PR, Brasil \\ ${ }^{2}$ Departamento de Física, Universidade Estadual de Maringá, Maringá, \\ PR, Brasil
}

Corresponding author: E. Düsman

E-mail: lisdusman@yahoo.com.br

Genet. Mol. Res. 13 (1): 2248-2258 (2014)

Received March 7, 2013

Accepted October 2, 2013

Published March 31, 2014

DOI http://dx.doi.org/10.4238/2014.March.31.5

\begin{abstract}
Radioactive iodine-131 (131I) is used in the treatment and diagnosis of thyroid gland injuries. However, because it emits ionizing radiation, it causes harmful effects to cells. Given that betacarotene (BC) has antioxidant and antigenotoxic properties, this study aimed to investigate its radioprotective and antimutagenic activity in relation to $131 \mathrm{I}$ at the dose that is used to treat hyperthyroidism using a test system of bone marrow cells from Wistar rats (Rattus norvegicus). The doses were $0.2 \mathrm{~mL}$ of $8 \mathrm{mg} \mathrm{BC} / \mathrm{mL}$ corn oil and $25 \mu \mathrm{Ci} 131 \mathrm{I}$ per 100 $\mathrm{g}$ body weight, and they were given via gavage in acute and subchronic treatments. Treatment groups included simultaneous, pre-treatment, post-treatment, and continuous treatment types. In all antimutagenic acute treatments, BC had a significant antimutagenic/radioprotective activity in relation to $131 \mathrm{I}$. In subchronic antimutagenic treatments, BC reduced the damage that was caused by the radioisotope; however, this reduction was not statistically significant because of the relatively low
\end{abstract}


percentage of chromosomal abnormalities that were observed with only 131I compared to the acute treatment. These results demonstrate the radioprotective and antimutagenic activity of $\mathrm{BC}$, indicating its use by the population, which inevitably is exposed to mutagenic agents, as a means of health protection.

Key words: Carotenoid; Mutagenicity; Natural compound; Radioisotope

\section{INTRODUCTION}

Epidemiological studies have shown that populations that frequently consume vegetables containing vitamins $\mathrm{A}, \mathrm{C}$, and $\mathrm{E}$ and beta-carotene $(\mathrm{BC})$ have a lower incidence and risk of developing cancer and heart disease. This indicates the role of these compounds as immune response regulators and as inhibitors of diseases mediated by free radicals (Lupulescu, 1994; Uenojo et al., 2007).

Iodine-131 (131I) is a radioisotope used for diagnosis and treatment, especially in thyroid cancer. However, it emits gamma and beta radiation, which are both dangerous because they induce multiple biological effects such as excessive free radicals leading to oxidative stress and causing harm to cell structures. Among these effects, the most harmful are the changes that occur in DNA molecules, causing genetic instability. Thus, many studies aiming to find radioprotective substances that possess antioxidant properties have been conducted because they act in the capture of free radicals, blocking or inhibiting their deleterious action (Biral, 2002; Pontual et al., 2004; Telesil and Machado, 2008; Limón-Pacheco and Gonsebatt, 2009).

$\mathrm{BC}$, a pigment naturally found in many fruits and vegetables, has one of the highest antioxidant potentials found among carotenoids (Ben-Amotz et al., 1996). Because of the antioxidant and antigenotoxic properties of $\mathrm{BC}$, it is being studied as a radioprotective agent in vitro (Konopacka and Rzeszowska-Wolny, 2001; Ortmann et al., 2004) and in vivo (Salvadori et al., 1996; Konopacka et al., 1998; El-Habit et al., 2000; Sisodia et al., 2004). This study aimed to evaluate the radioprotective and antimutagenic action of $\mathrm{BC}$ against the radioisotope 131I at the concentration that is used in the nuclear medicine therapy of hyperthyroidism in vivo using bone marrow cells of Wistar rats in acute and subchronic treatment.

\section{MATERIAL AND METHODS}

\section{Treatment solution}

The radioisotope 131I was obtained from the Institute of Energy and Nuclear Research, São Paulo, Brazil. The concentration used was $25 \mu \mathrm{Ci}$ or $0.925 \mathrm{MBq} / 100 \mathrm{~g}$ body weight (bw), which corresponds to the concentration that is used in the treatment of hyperthyroidism in humans and that caused a greater number of chromosomal changes in Wistar rat bone marrow cells (Düsman et al., 2011).

$\mathrm{BC}$ treatment solutions were prepared by Beta Bronze from the Herbarium Labo- 
ratório Botânico Ltda. (Curitiba, Brazil) and administered in doses of $0.2 \mathrm{~mL} / 100 \mathrm{~g}$ bw of the animal from a solution of $8 \mathrm{mg} \mathrm{BC} / \mathrm{mL}$ corn oil (Liza, Brazil). The dose was calculated by extrapolating to the rats the average dose for humans, which is 4-6 mg per day according to Dusinska et al. (2003).

\section{Wistar rats}

Wistar rats, Rattus norvegicus, were from the Central Vivarium of State University of Maringá (UEM), aged 35 days, and had approximately $100 \mathrm{~g}$ bw. Six animals were used for each control and treatment group, including three males and three females. The animals in each group were separated in polypropylene boxes and housed at the Laboratory of Mutagenesis/Radiation, Department of Biotechnology, Genetics and Cell Biology (UEM), under controlled temperature $\left(25^{\circ} \mathrm{C}\right)$ and humidity $(50 \%)$ with a 12 -h light/dark photoperiod according to rules established by the Ethics Committee on Experimentation with Laboratory Animals/ UEM (PRO 027/2009).

The negative control (CO-) in the experiment was made using $1 \mathrm{~mL}$ water $/ 100 \mathrm{~g}$ bw of the animal in a single dose (acute treatment) and once daily for 5 days (subchronic treatment), and the solvent was $0.5 \mathrm{~mL}$ corn oil $/ 100 \mathrm{~g}$ bw of the animal in a single dose (acute treatment).

The mutagenicity of $131 \mathrm{I}$ was assessed by sacrificing animals $24 \mathrm{~h}$ and 5 days $(120 \mathrm{~h})$ after the administration of $25 \mu \mathrm{Ci} 131 \mathrm{I} \mathrm{in} 1 \mathrm{~mL}$ water per $100 \mathrm{~g}$ bw in a single dose via gavage. $\mathrm{BC}$ at $0.2 \mathrm{~mL} / 100 \mathrm{~g} \mathrm{bw}$ was given in a single dose (acute treatment) and once daily for 5 days (subchronic treatment) via gavage.

The experimental antimutagenicity protocols involved acute $(24$ or $26 \mathrm{~h})$ and subchronic (6 or 11 days) treatments. Acute treatments included the following: simultaneous treatment (SIM), 131I + BC; pre-treatment (PRE), BC and after $2 \mathrm{~h}+131 \mathrm{I}$; and post-treatment (POST), 131I and after $2 \mathrm{~h}+\mathrm{BC}$. Subchronic treatments included the following: SIM, $131 \mathrm{I}+\mathrm{BC}$ with sacrifice on day 6; PRE, BC for 5 days and after $24 \mathrm{~h}+131 \mathrm{I}$ with sacrifice on day 11; POST, 131I and after $24 \mathrm{~h}$ BC for 4 days with sacrifice on day 6 ; and continuous (CONT), BC for 5 days, $24 \mathrm{~h}$ after 131I $+\mathrm{BC}$, and after $24 \mathrm{~h} \mathrm{BC}$ for 4 days with sacrifice on day 11 .

To verify the radiation elimination by the animals within the groups that received the radioisotope, the wood woll/bed placed in each box was standardized $(70 \mathrm{~g})$ and changed after every radiation measurement. Measurements of the exposure/radiation rate from each animal per group and the elimination/radiation of wood woll/bed from every box were made with the aid of a Geiger Muller (Excelsior Electronics CO), which was calibrated in 2008, immediately after the treatments, every $4 \mathrm{~h}$ for the first $12 \mathrm{~h}$, and every $24 \mathrm{~h}$, resulting in measurements at $0,4,8,12$, and $24 \mathrm{~h}$ for acute treatments and $0,4,8,12,24,48,72,96$, and $120 \mathrm{~h}$ for subchronic treatments.

Water and food (Nuvilab CR1, Paraná, Brazil) of all groups of animals were changed daily. To verify whether there was variation in water consumption in relation to radiation exposure, water consumption was measured daily in all groups every $4 \mathrm{~h}$ during the first 12 $\mathrm{h}$ and every $24 \mathrm{~h}$ in the subchronic treatment group. Food was suspended $2 \mathrm{~h}$ before and $2 \mathrm{~h}$ after treatment so the rats could fast, which is similar to what is indicated for human patients undergoing this type of radiotherapy. 


\section{Chromosomal aberration test}

A chromosome aberration test was performed to obtain bone marrow cells of Wistar rats using the method of Ford and Hamerton (1956), with modifications. In order to halt the mitotic cells in metaphase, $0.5 \mathrm{~mL} 0.16 \%$ colchicine (Acros Organics, USA) per $100 \mathrm{~g} \mathrm{bw}$ was administered $1.5 \mathrm{~h}$ before sacrifice. For the sacrifice, $0.5 \mathrm{~mL}$ thionembutal $(1 \mathrm{~g}$ sodium thiopental $/ 25 \mathrm{~mL}$ distilled water) (Abbott Labs. do Brasil Ltda., São Paulo, Brazil) was administered intraperitoneally.

Bone marrow was removed from the femurs with $5 \mathrm{~mL} 0.075 \mathrm{M}$ potassium chloride hypotonic solution (Labsinth, São Paulo, Brazil). The suspension was incubated (403/3N incubator, São Paulo, Brazil) at $37^{\circ} \mathrm{C}$ for $12 \mathrm{~min}$ and centrifuged for 5 min (Excelsa 3 centrifuge, São Paulo, Brazil), and the supernatant discarded. The material was fixed with $5 \mathrm{~mL}$ 3:1 methanol:acetic acid solution (Merck, Germany) and centrifuged for 5 min, and the supernatant was discarded. The fixative was changed at least twice. The preparation was done with a drop of suspension on clean slides containing a film of distilled water ice. The slides were stained by dripping a film of Giemsa (Merck) solution in phosphate buffer $\left(0.06 \mathrm{M} \mathrm{Na}_{2} \mathrm{HPO}_{4}\right.$ $\mathrm{x} 12 \mathrm{H}_{2} \mathrm{O}$ (Labsinth) and $0.06 \mathrm{M} \mathrm{KH}_{2} \mathrm{PO}_{4}$ (Vetec Química, Rio de Janeiro, Brazil) at a ratio of $1: 30$ and $\mathrm{pH} 6.8$ ).

The slides were blindly analyzed under a light microscope (Olympus KHC, Brazil). One hundred metaphases were analyzed per animal, totaling 600 per group. Alterations such as gaps, breaks, and fragments were noted.

The mitotic index (MI) for the cytotoxicity evaluation was calculated using 5000 cells per sex, totaling 10,000 cells per group. The MI percentage was calculated as the number of dividing cells divided by the total cells present in the fields.

\section{Statistical analysis}

Statistical analysis was performed using the chi-square test $(\alpha=0.05)$.

\section{RESULTS}

Figure 1 shows the MI and the percentage of chromosomal aberrations (CAs) of the control and acute treatments. The acute treatments (MI- BC, 1.7; 131I, 2.2; SIM, 1.2; PRE, 1.2; and POST, 1.3) had no statistical difference in the rate of cell division in relation to the controls (MI- $\mathrm{CO}^{-}, 1.4$ and CS - solvent group, 0.9). Regarding chromosomal abnormalities, $131 \mathrm{I}$ proved to be an inducer $(4.3 \%)$, with a significantly higher percentage of induction than the control ( $\mathrm{CO}^{-}, 0.3$ and $\left.\mathrm{CS}, 0.2\right), \mathrm{BC}(0.7)$, and the antimutagenic treatments (SIM, 0.8; PRE, 1.5; and POST, 1.2). PRE showed a statistically significant difference in the percentage of CAs relative to the two controls, negative and solvent, and POST also showed a significant difference relative to the control solvent.

Figure 2 shows the rate of radiation exposure and its elimination to the beds of all groups that were sacrificed after $24 \mathrm{~h}$. Regarding the exposure rate, the acute treatment with the highest value for the entire experiment was the SIM group. However, the same reduction in exposure rate (82.2\%) in $24 \mathrm{~h}$ was observed in all treatments. Regarding the elimination rate, 
which was measured every $4 \mathrm{~h}$, most treatments presented an increase at $8 \mathrm{~h}$, a decrease at 12 $\mathrm{h}$, and an increase at $24 \mathrm{~h}$.

\section{Acute}

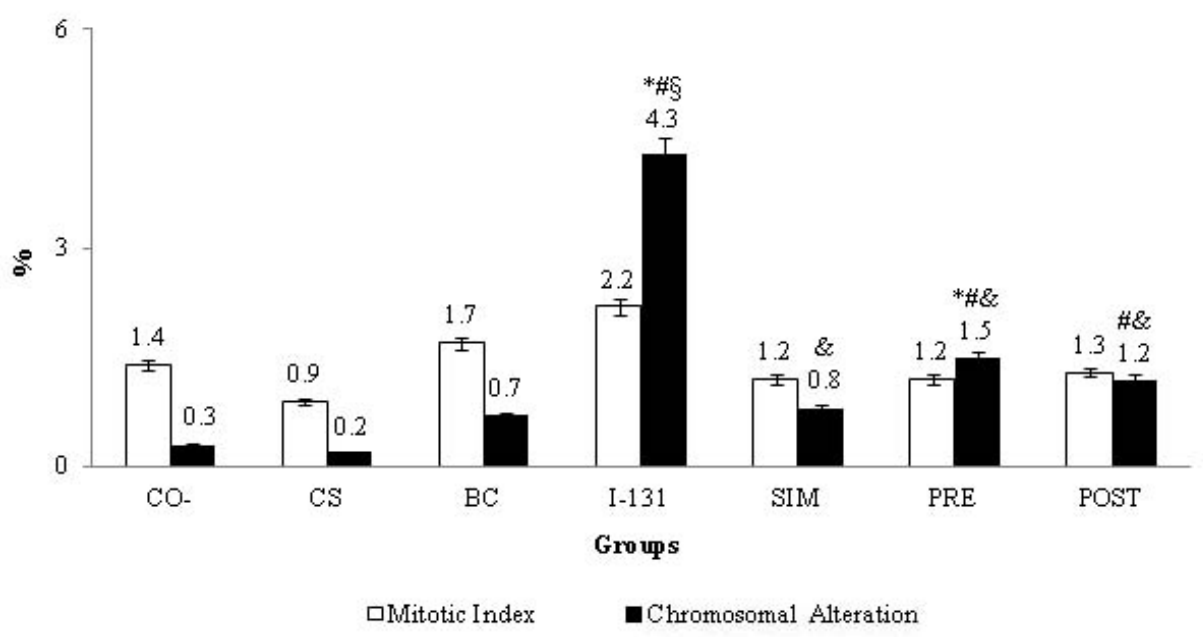

Figure 1. Mean mitotic index and percentage of chromosomal aberrations in the negative control group $\left(\mathrm{CO}^{-}\right)$and the solvent group (CS) and treated with beta-carotene (BC) and $131 \mathrm{I}^{1}$ in the acute treatment of Wistar rats; ${ }^{1}$ Results published in Düsman et al. (2011). Treatments: SIM = simultaneous; PRE = pre-treatment; POST = post-treatment. *Statistically significant result in relation to $\mathrm{CO}^{-}(\mathrm{P}<0.05)$. ${ }^{\text {\#Statistically significant result in relation to } \mathrm{CS}(\mathrm{P}<}$ 0.025). ${ }^{\S}$ Statistically significant result compared to $\mathrm{BC}(\mathrm{P}<0.005) .{ }^{\&}$ Statistically significant result compared to 131I $(\mathrm{P}<0.025)$.

\section{Sacrifice 24 hours}

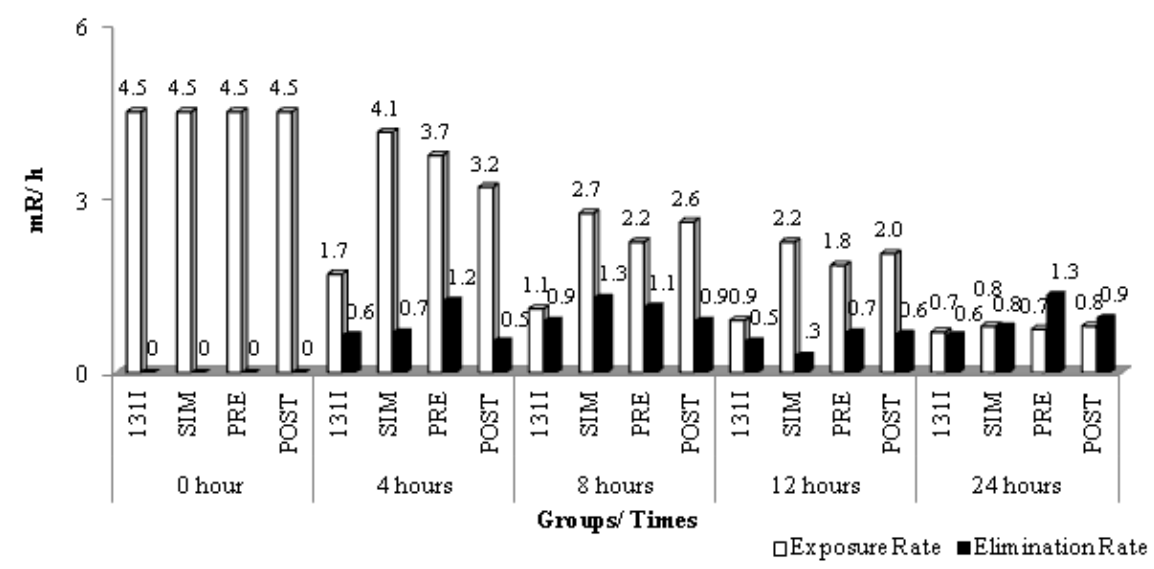

Figure 2. Rate of radiation exposure and elimination of 131I in acute treatments of Wistar rats. SIM = simultaneous; $\mathrm{PRE}=$ pre-treatment; POST $=$ post-treatment.

Figure 3 shows the MI and the percentage of CAs from all experimental groups that received the subchronic treatment. Statistical analysis showed no significant differences between 
the percentages of $\mathrm{MI}$ that were reported for controls $\left(\mathrm{CO}^{-}, 1.4\right.$ and $\left.\mathrm{CS}, 0.9\right)$, treatment with $\mathrm{BC}$ (1.1), 131I (1.6), and the four types of treatment with BC and 131I (SIM, 1.3; PRE, 1.1; POST, 1.3; and CONT, 1.2). The percentages of CAs that resulted from the SIM (1.2), POST (1.3), and CONT (1.3) treatments were statistically higher than that of the solvent control.

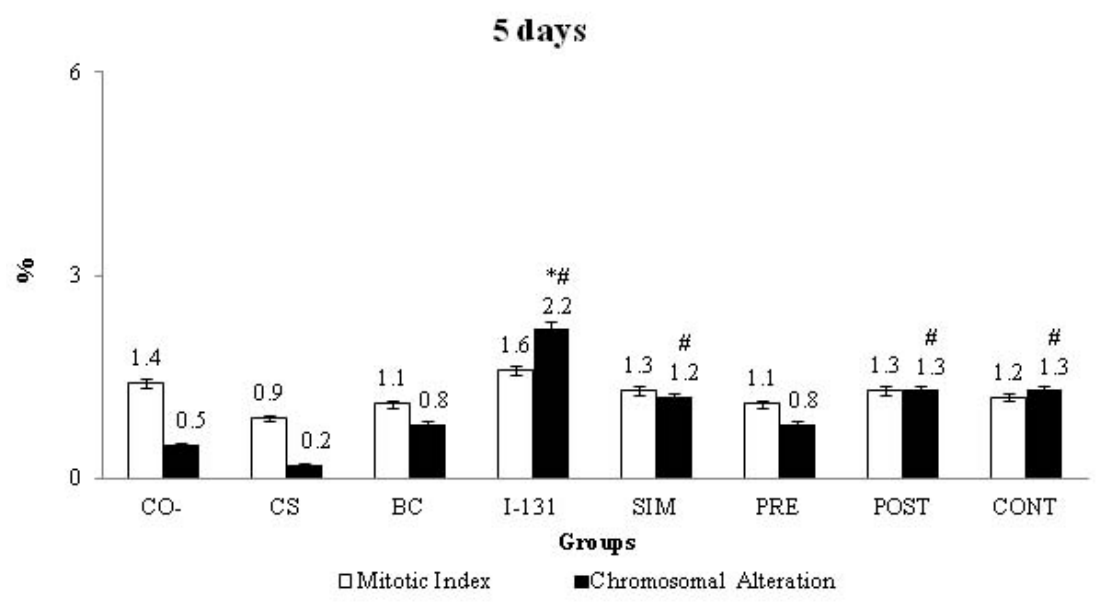

Figure 3. Percentages of mitotic index and chromosomal aberrations that were obtained from the negative control group $\left(\mathrm{CO}^{-}\right)$and the solvent group (CS) and beta-carotene $(\mathrm{BC})$ and $131 \mathrm{I}^{1}$ treatment in the subchronic treatment of Wistar rats. ${ }^{1}$ Results published in Düsman et al. (2011). Treatments: SIM = simultaneous; PRE = pre-treatment; $\mathrm{POST}=$ post-treatment; $\mathrm{CONT}=$ continuous. ${ }^{*}$ Statistically significant result in relation to $\mathrm{CO}^{-}(\mathrm{P}<0.025)$. ${ }^{\#}$ Statistically significant result in relation to CS $(\mathrm{P}<0.025)$.

The radiation rate exposure of the animals and its elimination to the beds were also measured in the subchronic treatment groups and are illustrated in Figure 4. All groups showed a reduction in the radiation exposure of animals in the first $24 \mathrm{~h}$ of the experiment. Continuous treatment showed the greatest decrease in the exposure rate $(86.7 \%)$, followed by POST (77.7\%), PRE (75.5\%), and SIM (73.3\%) in $24 \mathrm{~h}$. There was a noticeable reduction in the rate of elimination in all treatments in the beds at $48 \mathrm{~h}$; thereafter, there was a gradual decrease.

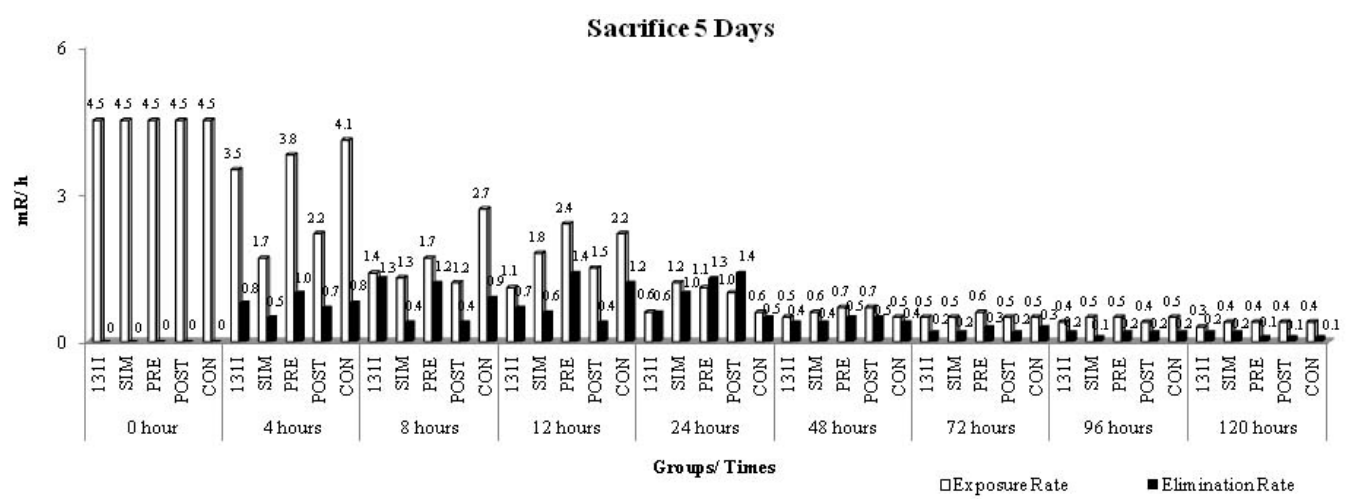

Figure 4. Rates of radiation exposure and elimination of 131I. Radiation exposure and elimination of 131I were measured at different times during the subchronic treatments. SIM = simultaneous; PRE = pre-treatment; POST = post-treatment; $\mathrm{CONT}=$ continuous. 
Water consumption of all acute and subchronic treatment groups is shown in Figure 5. Statistical analysis showed that animals of all antimutagenic groups, acute and subchronic, showed a significantly higher water consumption than their negative control counterparts and the animals that were treated with only BC or 131I. The group treated with 131I also showed significantly higher water consumption than the negative control and treatment with BC.

\section{Water Comsumption}

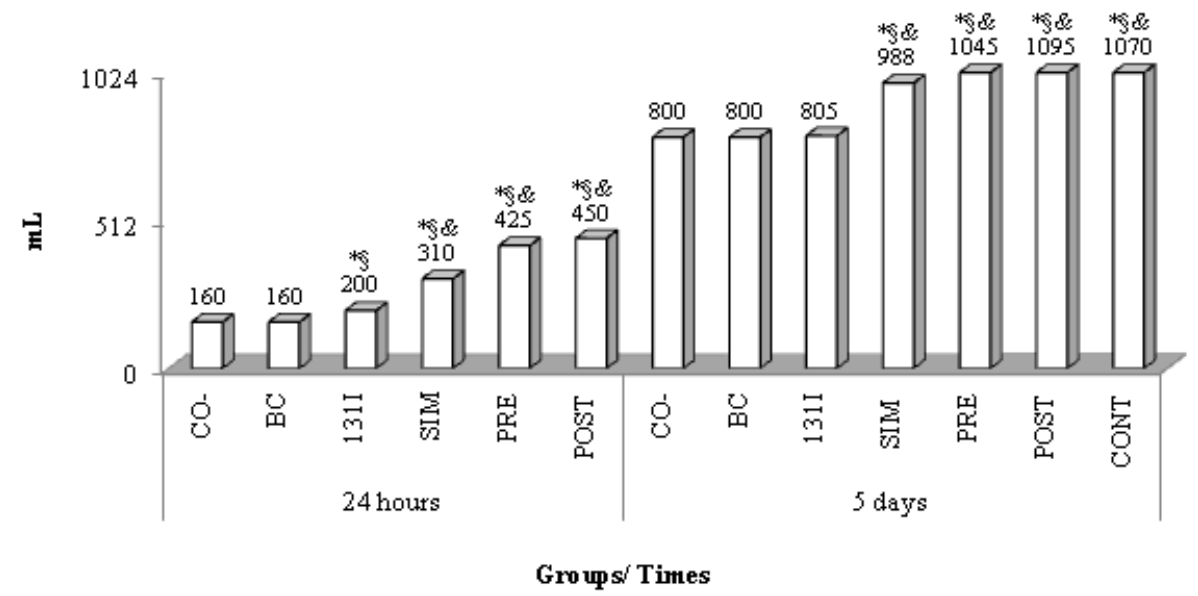

Figure 5. Water consumption was measured in different groups that were sacrificed after $24 \mathrm{~h}$ and 5 days of 131I administration. Treatments: $\mathrm{CO}^{-}=$negative control; $131 \mathrm{I}=$ treated with iodine- $131^{1}$; $\mathrm{SIM}=$ simultaneous; PRE $=$ pre-treatment; POST $=$ post-treatment CONT $=$ continuous. ${ }^{1}$ Results published in Düsman et al. (2011).

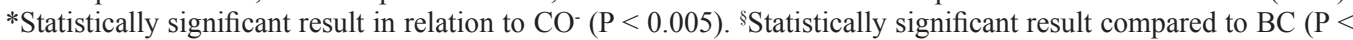
0.005). ${ }^{\text {SStatistically significant result in relation to } 131 \mathrm{I}(\mathrm{P}<0.005) .}$

\section{DISCUSSION}

The harmful effects resulting from ionizing radiation are related, in most cases, to the increased production of free radicals that cause damage to cellular macromolecules, especially DNA. Thus, a comprehensive approach has been made in the scientific community to identify antioxidant agents for their potential protective effect at the cellular level (El-Habit et al., 2000; Konopacka and Rzeszowska-Wolny, 2001; Hosseinimehr, 2010).

Because of the antioxidant and antigenotoxic properties of BC (Kammerer et al., 2001), it was assessed in this study. BC did not seem cytotoxic nor mutagenic in acute and subchronic treatments because it did not affect the cell division cycle and did not cause CAs in the bone marrow cells of the Wistar rats that were treated via gavage.

Our results from the $\mathrm{BC}$ treatments agree with those of other studies that were performed using bone marrow cells, like Heywood et al. (1985). Heywood et al. (1985) tested doses of $\mathrm{BC}$ in subchronic and chronic treatment of mice using the micronucleus test, and $\mathrm{BC}$ did not show mutagenicity. El-Habit et al. (2000) and El-Makawy and El-Ashmaoui (2003) also ascertained that $\mathrm{BC}$ did not increase the micronuclei in mice.

None of the treatments that evaluated the antimutagenicity of $\mathrm{BC}$ against the mutagenicity of the radioisotope 131I were cytotoxic. In addition, none of the treatments that 
administered only 131I was cytotoxic because there were no alterations in cell division. These results are different from those of El-Habit et al. (2000), who found that ionizing radiation decreased the MI of bone marrow cells of rats that were exposed to cesium-137.

In this study, the two treatments that included only 131I, with sacrifice after $24 \mathrm{~h}$ and 5 days, had significantly increased levels of CAs relative to their respective controls. This indicates the mutagenic activity of this radioisotope in bone marrow cells of Wistar rats. It can be inferred that the acute treatment analyzed only one cell division cycle, i.e., the cells that were sampled were directly treated. Unlike the subchronic treatment, in which the sacrifice 5 days after the administration of radioiodine allowed a longer time for the normal decay of the radioisotope, its almost complete elimination from the organism (93\%), cell death, and cell turnover explain the lower percentage of CAs that was seen in the group treated with $131 \mathrm{I}$ and sacrificed after 5 days (2.2\%) compared to the group that was treated and sacrificed after $24 \mathrm{~h}(4.3 \%)$.

Carotenoids are considered to have effective antioxidant, antimutagenic, and anticarcinogenic activities. Their protective effect has been accepted worldwide because they can scavenge singlet oxygen, extract peroxy radicals, modulate the carcinogenic process, block cell proliferation, stimulate communication between cells (gap junctions), and improve the immune system (Cemeli et al., 2009). These compounds have been indicated for patients because they are important in protecting against the adverse effects of radiotherapy, so that the benefits of this type of radiation do not exceed its harmful effects, as well as to protect the population from the consequences of unwanted radiation (Pontual et al., 2004; Hosseinimehr, 2007).

Weiss and Landauer (2003) described the action of various antioxidant nutrients and phytochemicals, including carotenoids, flavonoids, and vitamins A, C, and E, in protecting cells against ionizing radiation. This corroborates the results of this study, in which the SIM, PRE, and POST acute treatments showed radioprotective effects of $\mathrm{BC}$ against the mutagenicity of the radioisotope 131I in bone marrow cells of Wistar rats. That is, BC was effectively prepared and protected cells against the damaging effects of radioisotopes and inactivated the damage that was already caused by the activation of the repair system. The SIM treatment, which administered the carotenoid along with the radioisotope, showed the lowest percentage of CAs.

Considering that the percentage of CAs in the 131I treatment with sacrifice after 5 days was relatively low, no statistically significant difference was found in relation to any of the four antimutagenic subchronic treatments. Still, all treatments reduced the rate of CAs, which was evident by reductions of $45.4 \%$ in SIM, $63.6 \%$ in PRE, and $41 \%$ in POST and CONT. From these results, it seems that BC was the most efficient in PRE, when it was administered for 5 consecutive days before the 131I treatment and acted in cell preparation and protection before contact with the radionuclide.

These results are consistent with those from the study by Ben-Amotz et al. (1996), who observed the radioprotective activity of $\mathrm{BC}$ for 1 week in rats exposed to gamma rays; this carotenoid protected the liver and blood cells of animals against free radical damage induced by radiation. In addition, El-Habit et al. (2000) demonstrated the protective role of BC in rats at a concentration of $5 \mathrm{mg} / \mathrm{kg}$ bw against mutations induced by cesium-137 gamma radiation when $\mathrm{BC}$ was administered for 7 days before exposure to radiation. Thus, these studies corroborate the subchronic PRE results of this article, in which $\mathrm{BC}$ also reduced the damage in the genetic material when it was administered 5 days before 131I. This radioprotective activity of BC was confirmed by Abraham et al. (1993), who used the same cytogenetic test and same cell type for the same period and found that $\mathrm{BC}$ had a radioprotective effect in mice before irradiation with gamma rays. 
Konopacka et al. (1998) evaluated the effects of vitamins $\mathrm{C}$ and $\mathrm{E}$ and $\mathrm{BC}$ in bone marrow cells and exfoliated cells of bladder in mice against gamma radiation damage. The most effective protection against chromosomal damage and cytotoxicity was observed when the three components were administered together for 5 days before radiation, suggesting the occurrence of synergism between the components in the protection of cells. However, in both cell types, BC alone decreased the level of micronuclei when administered for 5 consecutive days before irradiation, acting as a radioprotective agent, as well as in the subchronic PRE group of this study, in which BC was administered for 5 consecutive days before the 131I. According to Konopacka et al. (1998), BC was more effective when administered immediately after gamma-ray irradiation. This can be compared to the results of our acute POST group with $131 \mathrm{I}$, in which $\mathrm{BC}$ acted as an efficient radioprotective agent.

In a study by Ben-Amotz et al. (1998), 709 children that were exposed to radiation from the Chernobyl nuclear accident, which occurred in Ukraine, and had conditions such as cancer and endocrine and mental disorders were subjected to a treatment for 3 months that was based on a diet supplemented with $40 \mathrm{mg}$ natural BC extracted from Dunaliella bardawil algae. Blood samples were obtained before and 1 and 3 months after supplementation with BC; they showed that irradiation increased the susceptibility to lipid oxidation, but BC was effective as a radioprotective agent and acted as an antioxidant.

Moreover, Sisodia et al. (2004) showed that BC protected cells against apoptosis induced by radiation when it was administered for 6 weeks in mice after exposure to gamma radiation. These results serve as an indication for oral administration of $\mathrm{BC}$ in clinical applications of radiotherapy. However, according to the results presented here, subchronic POST, in which beta-carotene was administered for 4 consecutive days after the radioisotope 131I, must be used with caution because the reduction was not significant; and POST and CONT reduced DNA damage caused by radiation the least compared with other subchronic treatments.

Konopacka and Rzeszowska-Wolny (2001) studied the effect of vitamins C and E and $\mathrm{BC}$ in human lymphocytes using the micronucleus test before and after exposure to radiation with cobalt- 60 . BC reduced the number of micronuclei that was induced by radiation at all doses evaluated. $\mathrm{BC}$ additions $5 \mathrm{~min}$ after irradiation was the most expressive treatment, which contradicted the result of adding BC 120 min after irradiation, where there was no significant reduction in micronuclei in lymphocytes. The overall results showed that the vitamins offered more protection when they were added immediately after exposure to cobalt- 60 than when they were added before irradiation.

The effects of $\mathrm{BC}$ against the damage of 131I on bone marrow cells of Wistar rats that were observed in this study are different from those that were observed by Salvadori et al. (1996), who used somatic cells (splenocytes, reticulocytes, and bone marrow) and germ cells of mice to assess the damage caused by X-rays Salvadori et al. (1996) observed that BC had a radioprotective effect except on bone marrow cells. In the experiment by Morales-Ramírez et al. (1998), BC increased the frequency of sister chromatid exchanges induced by gamma radiation in bone marrow cells of mice.

In this study, acute SIM showed the most efficient radioprotective activity of $\mathrm{BC}$, but all acute antimutagenic treatments had this activity against the 131I. This can be explained by its antioxidant properties; $\mathrm{BC}$ effectively reduces damage caused by free radicals that are formed by 131I, such as CAs. When it is administered before and concurrently with radiation, $\mathrm{BC}$ acts as an antioxidant, removing free radicals and preventing damage. When applied after radiation, $\mathrm{BC}$ stimulates the DNA repair system. Moreover, according to El-Habit et al. (2000), BC has a 
protective effect on the genetic material regardless of the nature of the genotoxins, which can be physical, such as ionizing radiation, or chemical, such as carcinogens and mutagens.

According to Reiners and Labmann (1999), 40-70\% of ingested radiation is normally excreted by the animals $24 \mathrm{~h}$ after administration. This event was observed in this study: the rate of radiation exposure of animals in all treatment groups, acute and subchronic, decreased clearly during the first $24 \mathrm{~h}$. Furthermore, despite small variations, it was observed that the elimination of radiation that was measured in the beds was high in the first $24 \mathrm{~h}, 82.2 \%$ for acute antimutagenic groups and between 73 and $86 \%$ for subchronic antimutagenic groups, and the CONT group highlighted the largest elimination (86.7\%). These data confirm the elimination of 131I radiation via feces, sweat, and urine, and thus proved that the animals did not accumulate radiation inside their bodies.

The water consumption of animals in all treatment groups was checked to establish if there is any connection between the ingestion of water and the radioisotope 131I. The data suggest that radiation may alter the metabolism of animals. According to statistical analysis, there was a significant increase in water consumption in treatment groups subjected to radiation, both in the acute and subchronic treatments.

Thus, this study clearly demonstrated the radioprotective and antimutagenic activity of $\mathrm{BC}$, which reduced the damage caused by ionizing radiation from 131I on bone marrow cells of rats treated in vivo. These data indicate the use of this natural carotenoid by the population, especially for patients with thyroid cancer, before, during, and after their exposure to radiation in diagnosis or therapy as a form of prevention and health protection.

\section{ACKNOWLEDGMENTS}

Research supported by the Coordination for the Improvement of Higher Level Personnel, CAPES, and the Laboratory of Mutagenesis and Environmental Monitoring staff of the State University of Maringá, UEM.

\section{Conflicts of interests}

The authors declare no conflict of interest.

\section{REFERENCES}

Abraham SK, Sarma L and Kesavan PC (1993). Protective effects of chlorogenic acid, curcumin and beta-carotene against gamma-radiation-induced in vivo chromosomal damage. Mutat. Res. 303: 109-112.

Ben-Amotz A, Rachmilevich B, Greenberg S, Sela M, et al. (1996). Natural beta-carotene and whole body irradiation in rats. Radiat. Environ. Biophys. 35: 285-288.

Ben-Amotz A, Yatziv S, Sela M, Greenberg S, et al. (1998). Effect of natural beta-carotene supplementation in children exposed to radiation from the Chernobyl accident. Radiat. Environ. Biophys. 37: 187-193.

Biral AR (2002). Radiações Ionizantes para Médicos, Físicos e Leigos. Insuls, Florianópolis.

Cemeli E, Baumgartner A and Anderson D (2009). Antioxidants and the comet assay. Mutat. Res. 681: 51-67.

Dusinska M, Kazimirova A, Barancokova M, Beno M, et al. (2003). Nutritional supplementation with antioxidants decreases chromosomal damage in humans. Mutagenesis 18: 371-376.

Düsman E, Berti AP, Mariucci RG, Lopes NB, et al. (2011). Mutagenicity of diagnostic and therapeutical doses of radiopharmaceutical iodine-131 in Wistar rats. Radiat. Environ. Biophys. 50: 579-584.

El-Habit OH, Saada HN, Azab KS, Abdel-Rahman M, et al. (2000). The modifying effect of beta-carotene on gamma radiation-induced elevation of oxidative reactions and genotoxicity in male rats. Mutat. Res. 466: 179-186. 
El-Makawy A and El-Ashmaoui HM (2003). Evaluation of the protective activity of beta-carotene and 1-carnitine on doxorubicin-induced genotoxicity in rats. Arab J. Biotechnol. 6: 289-296.

Ford CE and Hamerton JL (1956). A colchicine, hypotonic citrate, squash sequence for mammalian chromosomes. Stain Technol. 31: 247-251.

Heywood R, Palmer AK, Gregson RL and Hummler H (1985). The toxicity of beta-carotene. Toxicology 36: 91-100.

Hosseinimehr SJ (2007). Trends in the development of radioprotective agents. Drug Discov. Today 12: 794-805.

Hosseinimehr SJ (2010). Flavonoids and genomic instability induced by ionizing radiation. Drug Discov. Today 15: 907-918.

Kammerer C, Czermak I and Getoff N (2001). Radiation protecting properties of vitamin E-acetate and $\beta$-carotene. Radiat. Phys. Chem. 60: 71-72.

Konopacka M and Rzeszowska-Wolny J (2001). Antioxidant vitamins C, E and beta-carotene reduce DNA damage before as well as after gamma-ray irradiation of human lymphocytes in vitro. Mutat. Res. 491: 1-7.

Konopacka M, Widel M and Rzeszowska-Wolny J (1998). Modifying effect of vitamins C, E and beta-carotene against gamma-ray-induced DNA damage in mouse cells. Mutat. Res. 417: 85-94.

Limón-Pacheco J and Gonsebatt ME (2009). The role of antioxidants and antioxidant-related enzymes in protective responses to environmentally induced oxidative stress. Mutat. Res. 674: 137-147.

Lupulescu A (1994). The role of vitamins A, beta-carotene, E and C in cancer cell biology. Int. J. Vitam. Nutr. Res. 64: 3-14.

Morales-Ramírez P, Mendiola-Cruz MT and Cruz-Vallejo V (1998). Effect of vitamin C or beta-carotene on SCE induction by gamma rays in radiosensitized murine bone marrow cells in vivo. Mutagenesis 13: 139-144.

Ortmann EK, Mayerhofer T, Getoff N and Kodym R (2004). Effect of antioxidant vitamins on radiation-induced apoptosis in cells of a human lynphoblastic cell line. Radiat. Res. 161: 48-55.

Pontual MLA, Domingos AC and Almeida SM (2004). A importância dos radioprotetores na vida cotidiana. Humanidades: Rev. Ciênc. Educ. Cult. 2: 1 .

Reiners C and Lassmann M (1999). Radioiodine (131I) treatment of hyperthyroidism: radiation protection and quality assurance. Eur. J. Nucl. Med. 26: 683-685.

Salvadori DM, Ribeiro LR, Xiao Y, Boei JJ, et al. (1996). Radioprotection of $\beta$-carotene evaluated on mouse somatic and germ cells. Mutat. Res. 356: 163-170.

Sisodia R, Srivastava P, Nandchahal KK and Bhatia AL (2004). Significance of radiation apoptosis in cancer and its modification by beta carotene. Eur. J. Cancer 2: 70 .

Telesil M and Machado FA (2008). A influência do exercício físico e dos sistemas antioxidantes na formação de radicais livres no organismo humano. Rev. Saúde Biol. 1: 40-49.

Uenojo M, Maróstica-Junior MR and Pastore GM (2007). Carotenóides: Propriedades, aplicações e biotransformação para formação de compostos de aroma. Quím. Nova 30: 616-622.

Weiss JF and Landauer MR (2003). Protection against ionizing radiation by antioxidant nutrients and phytochemicals. Toxicology 189: 1-20. 